\title{
LA POLÍTICA MONETARIA DEL BCE ANTE EL TRIBUNAL CONSTITUCIONAL FEDERAL ALEMÁN: LA SENTENCIA DE 21 DE JUNIO DE 2016 EN EL CASO «OMT»
}

\author{
ANTONIO SÁINZ DE VICUÑA Y BARROSO' \\ antonio.sainzdevicuna@googlemail.com
}

Resumen

El presente artículo narra las vicisitudes de un litigio de cuatro años de duración ante el Tribunal Federal Constitucional Alemán, poniendo en cuestión la constitucionalidad del anuncio por el BCE en 2012 de un programa de intervenciones en los mercados secundarios de bonos soberanos. El pleito es singular por (a) su carácter puramente intra-alemán, esto es, entre litigantes solamente alemanes y sin que el BCE fuera parte del litigio constitucional a pesar de ser el autor del acto discutido; (b) el hecho de ser el primer litigio en su historia sobre el que el TCFA elevó una cuestión prejudicial al Tribunal de Justicia de la Unión Europea, con elementos ciertamente

\footnotetext{
Antonio Sáinz de Vicuña y Barroso es abogado del Estado. Ha sido general counsel (secretario general) del BCE. Actualmente es asesor externo de KPMG para Servicios Financieros. Las opiniones expresadas en el presente artículo son personales, en uso de la libertad de expresión académica.
} 
atípicos en este tipo de procesos de diálogo entre jurisdicciones; (c) la concurrencia del pleito constitucional con un nuevo programa del BCE de intervenciones masivas en los mercados secundarios de bonos soberanos, ejecutado por el Eurosistema, que no ha sido objeto de impugnación; (d) las peculiaridades de la sentencia final del TCFA del 21 junio 2016.

\title{
Palabras clave
}

Banco Central Europeo; Eurosistema; recurso prejudicial; Tribunal Constitucional Federal Alemán; política monetaria; política económica; euro; mercado de deuda pública.

\section{THE ECB MONETARY POLICY SCRUTINIZED BY THE GERMAN CONSTITUTIONAL COURT: THE JUDGMENT OF 21 JUNE 2016 IN THE OMT CASE}

\begin{abstract}
This article describes the several steps of a four-year long litigation before the German Federal Constitutional Court, concerning the compatibility with the German Constitution of the announcement by the ECB in 2012 of a program of possible interventions in the secondary sovereign bond market. This litigation is peculiar because of (a) its purely intra-German character, i.e. only between German parties, without the ECB being brought to that procedure in spite of being the author of the contested act; (b) the fact of this litigation being the first-ever case in the history of the German Constitutional Court having been submitted for a preliminary ruling by the European Court of Justice, albeit with elements somehow atypical for this kind of judicial dialogue; (c) the adoption by the ECB, and implementation by the Eurosystem, in spite of the ongoing litigation and concurrent with it, of a new program for interventions in the secondary sovereign bond markets, which has not been contested; and (d) the peculiarities of the final judgement of the German Federal Constitutional Court on 21 June 2016.
\end{abstract}

\section{Keywords}

European Central Bank; Eurosystem; reliminary ruling; German Federal Constitutional Court; monetary policy; economic policy; euro; public debt market.

\section{LA POLITIQUE MONÉTAIRE DU BCE DEVANT LA COUR CONSTITUTIONNELLE FÉDÉRALE ALLEMANDE: L'ARRÊT DU 21 JUIN 2016 DANS L'AFFAIRE OMT}

\section{Résumé}

Cet article décrit les étapes d'un litige de quatre ans devant la Cour constitutionnelle fédérale allemande, questionnant la constitutionalité fédérale de l'annonce 
par le BCE en 2012 d'un programme d'interventions dans les marchés secondaires de dette souveraine. Ce litige est singulier pour les raisons suivantes: (a) son caractère purement intra-allemand, entre litigants allemands et sans participation de la BCE comme partie au procès, même si la BCE était l'auteur de l'acte litigieux; (b) le fait que ce litige est le premier de l'histoire de la Cour constitutionnelle fédérale allemande à avoir été soumis á la Cour de justice de l’Union européenne a titre préjudiciel, avec des éléments certainement originaux pour ce type de procédures de dialogue entre tribunaux; (c) la concurrence de ce litige constitutionnel avec un nouveau programme du BCE d'interventions dans les marchés de dette souveraine, exécuté par l'Eurosystème, qui n'a pas été l'objet de contestations juridictionnelles; (d) les particularités de l'arrêt de la Cour constitutionnelle allemande, du 21 juin 2016.

\section{Mots clés}

Banque central européenne; Eurosystème; Questions préjudicielles; Cour constitutionnelle centrale allemande; Politique monétaire; Politique économique; Euro; Marché de dette publique. 


\section{SUMARIO}

I. LA CONSTITUCIÓN ALEMANA Y EL EURO. II. EL LITIGIO CONSTITUCIONAL SOBRE EL ANUNCIO POR EL PRESIDENTE DEL BCE DE UN NUEVO INSTRUMENTO DE POLITICA MONETARIA. III. EL RECURSO PREJUDICIAL DEL TCFA: 1. Las cuestiones formuladas; 2. Toma previa de posición por el TCFA; 3. Ofrecimiento simultáneo de un compromiso por el TCFA al TJUE: 3.1. Prohibición de la financiación monetaria; 3.2. Límite cuantitativo ex-ante; 3.3. Alejamiento del mercado primario de deuda pública; 4. Votos particulares del recurso prejudicial. III. LAS CONCLUSIONES DEL ABOGADO GENERAL DEL TJUE. IV. LA ADOPCIÓN DE UN PROGRAMA DE COMPRA DE VALORES POR EL BCE. V. LA SENTENCIA DEL TJUE EN VÍA PREJUDICIAL. VI. LA SENTENCIA FINAL DEL TCFA. VII. ALGUNAS CONCLUSIONES.

\section{LA CONSTITUCIÓN ALEMANA Y EL EURO}

El Tribunal Constitucional Federal Alemán («TCFA», en adelante) ha sido llamado a decidir en varias ocasiones acerca de la compatibilidad de la Unión Económica y Monetaria ( $U E M »$, en lo sucesivo) establecida en el Tratado de Maastricht, con la Ley Fundamental Alemana («LFA», en adelante). A raíz de la sentencia Brunner de 1992 sobre la ratificación del Tratado de Maastricht ${ }^{2}$, corroborada en este aspecto por la sentencia de 1998

2 Conocida como Sentencia Maastricht. BVerfGE 89, 155. Resumidamente, el TFCA admite la constitucionalidad del Tratado de Maastricht siempre y cuando la UEM mantenga el carácter de "Comunidad de Estabilidad» (Stabilitätsgemeinschaft), basada en la primacía del objetivo de estabilidad de precios para el BCE y en la independencia del Eurosistema. En el texto de la Sentencia Brunner se lee (traducción del autor): «El Tribunal Constitucional Federal examina si los instrumentos jurídicos de las instituciones y agencias europeas se mantienen dentro de los límites de los poderes a ellas conferidos o si se exceden en los mismos. El poder de revisión del Tribunal Federal Constitucional Alemán incluye el análisis de si los actos de las instituciones y agencias 
sobre la participación de Alemania en la tercera fase de la $\mathrm{UEM}^{3}$, el TCFA se autodeclara garante del núcleo identitario de la República Federal de Alemania recogido en la LFA (Identitätskern Deutschlands), que es intocable por el derecho de la Unión Europea («UE», en lo sucesivo) ${ }^{4}$. En ese núcleo identitario se encuentra no solo el principio de estabilidad monetaria, sino también el principio democrático y, en su aplicación, la necesaria participación del Parlamento Federal Alemán en la determinación de los ingresos y gastos del Estado. En la sentencia del TCFA sobre la ratificación del Tratado de Lisboa ${ }^{5}$, se reitera y desarrolla la doctrina anterior.

En 2010 la asociación alemana "Más democracia para Europa» (Mehr Demokratie für Europa $)^{6}$, junto con el grupo parlamentario comunista del Bundestag, denominado «La Izquierda» (Die Linke), un parlamentario euroescéptico bávaro (CSU) y el pequeño grupo de académicos que habían sido los demandantes en los anteriormente mencionados pleitos constitucionales, cuestionaron ante el TCFA la constitucionalidad de la ley alemana que autorizó los mecanismos de rescate de Grecia acordados en mayo 2010 por el Consejo de la $\mathrm{UE}^{7}$. Dicho pleito cuestionaba no solo la compatibilidad de los rescates con el principio democrático, sino también con el derecho fundamental de propiedad (al entender que el rescate con fondos públicos a Grecia ponía en peligro los ahorros de los alemanes). La sentencia de 7 septiembre 2011 del TCFA ${ }^{8}$ consideró que los citados mecanismos de rescate eran compatibles con la LFA, sujeto a la introducción de ciertos requisitos de orden

europeas van manifiestamente más allá de los poderes atribuidos a ellas, o si afectan al núcleo de identidad constitucional que no puede ser transferido. La Unión se considera a sí misma como una comunidad jurídica; en particular, se rige por el principio de atribución y por los derechos fundamentales, y respeta la identidad constitucional de los Estados miembros».

3 BVerfGE 97, 350; resumidamente, declara que la participación alemana en la tercera fase de la UEM, bajo las condiciones recogidas en la sentencia Brunner, no es contraria al Identitätskern alemán.

4 El respeto por la UE a la identidad constitucional de los Estados miembros se encuentra establecida en el art. 4 (2) TUE.

5 BVerfGE 123.

6 Asociación que tras una campaña publicitaria consiguió el apoyo de unos 12000 ciudadanos alemanes.

7 Los mecanismos de rescate a Grecia acordados por el Eurogrupo el 3 mayo 2010 fueron tres: el Fondo Europeo de Estabilidad Financiera (EFSF) el Mecanismo Europeo de Estabilidad Financiera (EFSM), y el crédito bilateral concedido a Grecia por los Estados del euro, con la excepción de Eslovaquia.

8 BVerfGE 125 y 126. 
procedimental en el reglamento del Parlamento Federal alemán para asegurar mejor el control democrático de la cuantía y evolución de cada decisión individual de rescate, evitar mecanismos automáticos y hacer participar al pleno del Bundestag en determinados casos.

El mencionado grupo demandante interpuso nueva demanda ante el TCFA en 2012, contra la ley alemana de ratificación del Tratado constitutivo del Mecanismo Europeo de Estabilidad (MEDE, o en sus siglas inglesas ESM), y contra la ley de ratificación del Tratado de Estabilidad, Coordinación y Gobernanza en la Unión Económica y Monetaria (conocido como Fiscal Compact).

\section{EL LITIGIO CONSTITUCIONAL SOBRE EL ANUNCIO POR EL PRESIDENTE DEL BCE DE UN NUEVO INSTRUMENTO DE POLITICA MONETARIA}

El 12 septiembre 2012, el mencionado grupo demandante amplió la demanda mencionada anteriormente para cuestionar el anuncio, el 6 septiembre 2012, del presidente del BCE, de un proyecto para sustituir el programa de intervenciones del Eurosistema en el mercado de bonos soberanos denominado Programa de Mercado de Valores (Securities Market Program o SMP), establecido en 2010, por un programa más elaborado de intervenciones del Eurosistema en dicho mercado, con la denominación de «Operaciones Monetarias Directas» (Outright Monetary Transactions o OMT). El programa SMP se puso en marcha por el Eurosistema a raíz de la crisis griega, sin que fuera impugnado ante los tribunales ${ }^{9}$. El programa OMT — que es condicional y nunca ha entrado en vigor-, a diferencia del programa SMP, que dejó de utilizarse, tenía la finalidad de atender las insuficiencias del programa SMP exigiendo como requisito la puesta en marcha de un programa del MEDE que impusiera al país con dificultades de financiación unas reformas estructurales y presupuestarias, y cuyos términos incluyeran a) intervenciones del MEDE en el mercado primario de bonos soberanos, y b) la participación con un programa similar del Fondo Monetario Internacional. Por su naturaleza de instrumento de política monetaria, requiere para su puesta en práctica un

9 Pero con la importante y activa oposición del Bundesbank. En abril de 2011 dimitió el gobernador del Bundesbank, Axel Weber, que estaba llamado a suceder al presidente J. C. Trichet como presidente del BCE, y en diciembre de 2011 dimitió el miembro alemán del Comité Ejecutivo del BCE, antiguo vicepresidente del Bundesbank, Jürgen Stark, cuando le quedaban varios años de mandato. 
funcionamiento anómalo de los mercados de deuda soberana, que perjudica la transmisión de dicha política a los niveles de precios. Se trata, por tanto, de un programa condicional y subsidiario a los del MEDE.

Este último litigio constitucional acerca del BCE es el objeto de la presente nota y quisiera indicar tres cuestiones a título de introducción de este contencioso.

Lo primero es que el BCE no adoptó el 6 de septiembre 2012 ningún acto jurídico. El objeto del litigio constitucional es un anuncio: el Consejo de Gobierno anunció en rueda de prensa su intención de incorporar a su elenco de posibles instrumentos monetarios un nuevo programa, denominado OMT, cuyas características básicas iniciales se expusieron en un comunicado de prensa, disponible en la página web del BCE solo en idioma inglés. Es un acto preparatorio de futuros actos jurídicos, de tipo programático, cuya materialización está sujeta a futuros elementos, propios y ajenos. Un examen del Diario Oficial de la Unión Europea (en adelante, «DOUE»), donde se publican los actos normativos del BCE, no permitirá encontrar un texto legal sobre el programa OMT.

La utilización del programa OMT, aparte de los requisitos citados más arriba, hubiera requerido una decisión formal del Consejo de Gobierno del BCE, específica para cada país afectado, explicitando el programa MEDE-FMI en el que se basa, así como las condiciones del mismo, acto jurídico que es necesario publicar en el DOUE para que surtiera efecto, y recurrible en vía judicial. El Consejo del BCE se reserva total discrecionalidad en la adopción de una decisión para activar, suspender y terminar el programa OMT. La terminación del programa en todo caso ocurriría, según el anuncio recurrido, si a) hay incumplimiento de los compromisos de reformas estructurales; b) si las intervenciones han cumplido su objetivo y el mercado deja de comportarse anómalamente, o c) discrecionalmente por el BCE. Piénsese que el anuncio del BCE se produce un 6 de septiembre, recién terminada la sesión del Consejo de Gobierno, y los recurrentes interponen su reclamación apenas seis días más tarde, sin tiempo material para que el BCE hubiera podido preparar y adoptar un acto jurídico (lo que, por cierto, hasta la fecha no ha sido necesario hacer).

En sintonía con lo anterior, y a pesar de cierta jurisprudencia esporádica del Tribunal de Justicia de la Unión Europea (en adelante, «TJUE») favorable a la admisibilidad de recursos contra actos no jurídicos de las instituciones ${ }^{10}$, en su auto de 10 diciembre 2013 en el asunto von Storch y otros

10 Otro caso referente al BCE es la sentencia del Tribunal General de 4 de marzo de 2015 (T-496/11 Reino Unido/ BCE), que consideró — muy discutiblemente- que un mero «informe» del BCE era un acto recurrible. 
$/ B C E^{11}$, relativo a la demanda de anulación contra el anuncio del BCE de 6 septiembre 2012 sobre el programa OMT por parte de un grupo de 5217 ciudadanos alemanes, el Tribunal General declaró su inadmisibilidad por entender que en ese anuncio del programa OMT no había acto jurídico recurrible, además de por falta de legitimación activa de los recurrentes.

El TCFA pudo haberse basado en dicho auto von Storch y otros /BCE para inadmitir ad limina la demanda contra el anuncio de dicho programa. Sin embargo, el TCFA no solo no lo hizo, sino que, según dijo en el recurso prejudicial ante el TJUE, saltó sobre dicha ausencia de acto legal recurrible con la argumentación de que los criterios del derecho de la Unión no predeterminan una «revisión preventiva de acuerdo con el Derecho alemán ${ }^{12}$. Cabe aquí señalar que, en mi opinión, la doctrina del TCFA sobre el «control preventivo de actos no-jurídicos» es difícilmente compatible con la idea de que los tribunales no sustituyen a las instituciones, sino que su mandato estricto es el control de legalidad, en este caso la legalidad constitucional alemana. Desde el momento en que el TCFA considera revisables con carácter preventivo actos de tipo programático y actos preparatorios, se abre una puerta para el activismo judicial incompatible con la función revisora de la judicatura. La política monetaria, por ejemplo, no consiste solo en medidas jurídicas, sino en gran parte en meras declaraciones cuya intención es influir en la conducta de los mercados: ¿van a ser meras declaraciones también objeto de posible revisión judicial?, ¿̇no se produce así una sustitución institucional de la administración competente y responsable por la autoridad judicial?, ¿no se está traspasando el dominio del derecho y se entra en el ámbito de la política?

Lo segundo que hay que señalar es que el objeto real de la litis es un acto del BCE, esto es, de una institución europea, por lo que el tribunal competente para enjuiciar la legalidad de los actos de esta institución es

11 Auto del Tribunal General de 10 de diciembre de 2013, von Storch y otros/BCE (T492/12, EU:T:2013:702).

12 Extractos del recurso prejudicial interpuesto por el TFCA ante el TJUE el 14 enero 2014 (traducción del autor): «La admisibilidad de la demanda constitucional no depende de si la Decisión OMT puede considerarse como un acto con efectos externos o como el anuncio de un acto posterior. También es irrelevante para el presente procedimiento determinar si la Decisión OMT afecta directamente a los demandantes, en el sentido del art. 263 sec. 4 TFUE». Según el TFCA, «la jurisprudencia del Tribunal Constitucional Federal reconoce que la protección jurídica preventiva puede ser necesaria en procedimientos de constitucionalidad para evitar ulteriores consecuencias que no se podrán corregir». 
el TJUE, y no un tribunal nacional. Ello debería conllevar el rechazo ad limina por el TCFA de las pretensiones de los recurrentes. Sin embargo, el TCFA se plegó a la original estratagema de los recurrentes, consistente en evitar la clara inadmisibilidad de su demanda disfrazando el pleito como un Organstreit ${ }^{13}$, en el que el demandado no es el BCE, autor del anuncio OMT que se impugna, sino que son demandados el Gobierno y el Parlamento alemanes bajo la acusación de que tenían que haber litigado ante el TJUE contra el anuncio de BCE. Insólito. Tras cuatro años de litigio, en su sentencia de 21 junio 2016, ${ }^{14}$ el TCFA declara las demandas "parcialmente inadmisibles, en la medida en que estas cuestionan directamente actos del BCE». La «parcialidad» de esa inadmisibilidad se refiere a aquellos demandantes que impugnaron ante el TCFA el anuncio del BCE, en vez de litigar contra el Parlamento y Gobierno alemanes como otros; en todo caso esa inadmisibilidad parcial no tiene efectos, ya que el TCFA entra en el fondo del asunto en su sentencia, en un pronunciamiento del que se benefician todos los demandantes.

Finalmente, hay que decir que el BCE, autor del «acto» enjuiciado, no fue parte en el proceso. El derecho fundamental de defensa ${ }^{15}$, al no ser parte procesal en el proceso constitucional, no lo pudo ejercitar; fue un espectador en un pleito inter alios; y las partes litigantes eran todas ellas alemanas, siendo así que la acción recurrida del BCE tenía por destinatarios a los países de toda el área monetaria. Solamente al plantearse posteriormente por el TCFA la cuestión prejudicial pudo el BCE defender la legalidad de su actuación ${ }^{16}$ ante el TJUE.

13 Disputa contra instituciones alemanas.

14 Sentencia del 21 junio 2016 (idioma alemán): http://www.bundesverfassungsgericht. de/SharedDocs/Entscheidungen/DE/2016/06/rs20160621_2bvr272813.html; resumen en inglés: https://www.bundesverfassungsgericht.de/SharedDocs/Pressemitteilungen/EN/2016/bvg16-034.html

15 El art. 103 de la Ley Fundamental Alemana, declara que «todos tienen el derecho de ser oídos ante los tribunales.» El art. 48 de la Carta Europea de Derechos Fundamentales dice que «se garantizará el derecho de defensa». El art. 6 del Convenio para la Protección de los Derechos Fundamentales del Consejo de Europea, titulado «Derecho a un proceso equitativo", reconoce también el derecho a ser oído en el proceso.

16 En la fase de prueba ante el TFCA, convocó este una docena de peritos, todos ellos alemanes, e invitó al BCE a participar como perito, para explicar al tribunal la situación económica que motivó su anuncio del programa OMT, sin autorizarle para argumentar jurídicamente. Acudió como perito del BCE el miembro alemán de su Comité Ejecutivo, dada la lengua del procedimiento, el economista Jörg Asmussen. 


\section{EL RECURSO PREJUDICIAL DEL TCFA}

\section{LAS CUESTIONES FORMULADAS}

El 14 de enero de 2014, el TCFA decidió elevar recurso prejudicial al TJUE $^{17}$ acerca de la alegación de violación del TFUE por el BCE en su decisión de 6 septiembre 2012 anunciando el programa OMT.

Un hecho es claramente positivo en este procedimiento: por primera vez en su historia, el TCFA ha elevado un recurso prejudicial al TJUE. En efecto, a pesar de que el TFUE en su art. 267 impone a los tribunales «cuyas decisiones no sean susceptibles de ulterior recurso judicial de derecho interno» la obligación jurídica de «someter la cuestión» al TJUE, lo cierto es que el TCFA nunca antes había elevado recurso prejudicial al TJUE, en clara violación del Tratado. Cabe, por tanto, considerar como un paso positivo el hecho de que el TCFA haya rectificado su conducta anterior —más de medio siglo después de la ratificación alemana del Tratado de Roma - planteando la primera - y por ahora única - cuestión prejudicial ante el TJUE sobre la legalidad de un acto de una institución europea.

Las preguntas al TJUE fueron las siguientes:

- Primera. Alegación de ultra vires.

¿Está o no el programa OMT fuera de la competencia estatutaria del $\mathrm{BCE}$, de política monetaria, al incidir las intervenciones del Eurosistema en el mercado de deuda pública en la política social y económica de algunos Estados miembros, de competencia puramente nacional —salvo medidas de coordinación europeas (Ecofin, Eurogrupo, Mecanismo Europeo de Estabilidad)_, pudiendo el BCE interferir con las políticas de los Estados y de la UE? Se argumenta que si el programa OMT tuviera la naturaleza de programa de "política social y económica», estaría claro que quedaba fuera de las competencias estatutarias del BCE, por corresponder dichas políticas a los Estados y a la $\mathrm{UE}^{18}$.

Complementan esta pregunta dudas acerca de la «proporcionalidad» del programa OMT, esto es, la falta de justificación acerca de si es o no necesario y adecuado para obtener los fines que se pretenden. Y razona

17 Registrado en el TJUE el 10 de febrero 2014 como asunto núm. C-62/14. Texto en inglés en: http://www.bverfg.de/entscheidungen/rs20140114B2bvr2213en.html.

18 Si la alegación de ultra vires se reconociera, el principio democrático (control por órganos democráticos de la RFA) requeriría según el TFCA una participación del Bundestag en la activación del programa OMT. 
también el TCFA que el hecho de que, por definición, el programa OMT sea "selectivo", aplicable a uno o varios Estados pero no con carácter general a todos, es indicio de su naturaleza «económica» más que "política monetaria» — que tiene sus efectos en todos los Estados de la zona euro-.

- Segunda. Alegación de violación de la prohibición estatutaria al Eurosistema de financiar mediante la expansión monetaria al sector público.

¿Viola el art. 123 TFUE, en particular dado el tratamiento pari passu del Eurosistema, en igualdad con los de los inversores privados (es decir, sin tener un rango preferente en caso de renegociación de deuda)? El TCFA razona que el art. 123 TFUE es una de las bases fundamentales de la «Comunidad de estabilidad» (Stabilitätsgemeinschaft) que es parte del núcleo constitucional básico en Alemania que permitió en su día la ratificación del TFUE, por lo que una violación masiva de esa prohibición de financiación monetaria vulneraría el ámbito «intocable» de la Constitución germana, en el que el Derecho de la UE no puede interferir.

\section{TOMA PREVIA DE POSICIÓN POR EL TCFA}

En contra de la práctica habitual en las cuestiones prejudiciales, en las que el Tribunal que eleva la cuestión la presenta con objetividad al TJUE, las preguntas sometidas por el TCFA al TJUE no se plantearon con neutralidad: el TCFA anticipa al TJUE las respuestas que a su juicio merecen las preguntas que el propio tribunal formula al juez europeo.

En primer lugar, el TCFA le dice al $\mathrm{TJUE}^{19}$ respecto a si el BCE actuó dentro de sus poderes estatutarios o no (control de ultra vires): "El TCFA considera la Decisión OMT incompatible con el art. 119 y art. 123.1 y 2 TFUE y con el art. 1 y siguientes del Estatuto del BCE ya que va más allá del mandato del $\mathrm{BCE}$ tal y como se regula en dichos preceptos, afectando a las competencias de los Estados miembros sobre política económica. El BCE es competente para la política monetaria. La competencia para la política económica, salvo para algunos supuestos, permanece en los Estados miembros». En relación con el principio democrático aplicable a las políticas social y económica: «Para cumplir con el principio democrático, la interpretación del mandato del BCE debe ser estricta. Para Alemania, el TCFA ha mantenido que la legitimación democrática que se deriva de las elecciones en los Estados miembros se ha restringido al transferirse el poder monetario a un BCE independiente, afectando al principio democrático». En relación con el

19 Traducción del autor. 
principio de atribución (art. 5.2 TUE): «Sería incompatible con el principio de atribución el que una institución de la UE autónomamente determine las competencias a ella atribuidas». El TCFA alega ante el TJUE, además, que el propio TJUE en su sentencia Pringle ${ }^{20}$ relativa a la compatibilidad del MEDE con el art. 123 TFUE (prohibición de financiación monetaria), ha establecido que las intervenciones del MEDE en los mercados primario y secundario de deuda pública no son "política monetaria», sino "política económica y fiscal» de los Estados (concluyendo en el caso Pringle, que el art. 123 TFUE no es en dicho caso relevante, ya que la prohibición de financiación monetaria se aplica solo a los bancos centrales y no al MEDE). De donde el TCFA deduce que el programa OMT al ser también de intervención en los mercados de deuda pública debe calificarse como "política económica y fiscal», siguiendo los razonamientos del propio TJUE, y no "política monetaria», entrando así el BCE en terreno ultra vires.

El recurso prejudicial del TCFA afirma también ante el TJUE el carácter ultra vires que tiene el $\mathrm{BCE}$ al mencionar como objetivo suyo la preservación del euro, en un tiempo - 2012 - en el que todos los mercados apostaban por una ruptura del área monetaria. Dice el TCFA ${ }^{21}$ : «Por cuanto hace a la pretensión del BCE de salvaguardar con la Decisión OMT la composición actual del área del euro (cf. comunicado de prensa del BCE del 26 julio 2012), obviamente no es una tarea que pertenezca a la política monetaria, sino a la política económica, que es competencia de los Estados miembros». Atenta al sentido común que el mandato del BCE sea prioritariamente la estabilidad de precios, cuando el presupuesto para ella es la existencia de la moneda que emite y cuya estabilidad debe proteger; la desaparición del euro — aparte de introducir volatilidades en las monedas nacionales de nuevo cuño, y afectar negativamente a la estabilidad de los precios-, haría inútiles todas las disposiciones del TFUE acerca de la UEM, y en particular la propia existencia del BCE; es decir, sería un contrasentido evidente. El mandato de estabilidad monetaria del BCE conlleva implícitamente el de salvaguardar la propia existencia de la moneda, naturalmente con los instrumentos que el TFUE ha puesto a su disposición.

El hecho de que el mandato del BCE incluya el objetivo secundario de apoyar la política económica de la Unión, entre la que se encuentra natu-

\footnotetext{
20 Sentencia TJUE del 27 Noviembre 2012. El caso Pringle cuestionaba la compatibilidad del MEDE con los arts. 123 (prohibición de la financiación monetaria del sector público) y 125 (regla de no responsabilidad de un Estado por las deudas de otro — «no bail-out rule»-) del TFUE.

21 Traducción del autor.
} 
ralmente la preservación del euro, se despacha por el TCFA con el siguiente argumento: «Para el TCFA, la compra de deuda pública en base a la Decisión OMT excede del objetivo de apoyar las políticas económicas generales de la UE que el BCE puede realizar (art. 119 sec. 2, art. 12 sec. 1 párr. 2 TFUE)». Preservar la moneda única, ambición de la UE desde la ruptura del sistema de Bretton Woods en 1971 (Plan Werner en los años setenta, SME en los ochenta, Maastricht para los noventa), necesidad evidente para conseguir un mercado interior único con una moneda estable y única, «excede» - TCFA dixit - del apoyo del BCE al salvamento del euro. Hay que decir que la mecánica de los mercados es tal que, conocida una intervención puntual del $\mathrm{BCE}$, o su mero anuncio, se produce un inmediato alineamiento de los demás agentes; es decir, que con una inversión de, por ejemplo, 5, la respuesta del mercado es, por ejemplo, de 100; nadie que no sea un banco central, por su capacidad ilimitada de intervención, es capaz de producir ese efecto magnificador. El mero anuncio verbal de una intervención de un banco central (forward guidance) produce, sin inversión monetaria, el efecto pretendido. Por ello, la intervención produce no una financiación del banco central al Estado, sino una reacción en el mercado que hace que este, y no aquel, sea quien alcance los efectos deseados.

Finalmente, dice el TCFA en apoyo de su anticipada y sesgada conclusión de que el programa OMT no es política monetaria y, por tanto, es ultra vires, que ${ }^{22}$ : «Para el TCFA, el objetivo manifestado por el BCE para justificar la Decisión OMT, corregir la disrupción del mecanismo de transmisión de la política monetaria, no cambia la transgresión mencionada del mandato del $\mathrm{BCE}$, ni la violación de la prohibición de financiación monetaria del sector público. [...] El hecho de que la compra de deuda pública pueda, bajo ciertas condiciones, ayudar a alcanzar los objetivos de la política monetaria del SEBC, no convierte la Decisión OMT en un instrumento de política monetaria». Por un lado, admite el TCFA que el programa OMT apoya la política monetaria, en contradicción con otros razonamientos anteriores; pero — sigue diciendo- su carácter marginal respecto de otros instrumentos de política monetaria — a juicio del TCFA — lo desnaturaliza y transforma en "política económica» y pasa por ello a ser ultra vires. No podemos seguir esa lógica, contraria además al TFUE y al Estatuto del BCE: tiene este el poder de «definir» y de «instrumentar» la política monetaria, y si se admite que el programa OMT al menos ayuda a la política monetaria no parece haber una lógica convincente para concluir que el BCE actúa ultra vires, salvo que se quiera sesgadamente mutilar las capacidades del BCE.

22 Traducción del autor. 
El TCFA señala que el programa OMT es política económica ya que es «selectivo»: solo se aplica a algunos países con problemas presupuestarios, y no a todos los de la zona monetaria. Ello incide, además, en una violación del principio de igualdad de trato y en discriminación por países. Dice el TCFA en su recurso prejudicial del 14 enero 2014 al TJUE ${ }^{23}$ : "Dado que la Decisión OMT persigue la compra puntual de deuda pública de ciertos Estados Miembros, las primas de riesgo de dicha deuda se adaptan a los cambios que dichas compras causan en las condiciones del mercado, poniendo en desventaja los títulos de deuda pública emitidos por otros Estados miembros».

Dos rápidos comentarios merece esta última argumentación del TCFA: en primer lugar, el programa OMT se anuncia sin discriminación nacional alguna: lo mismo podría aplicarse a un país que a otro; el programa OMT sería de aplicación a aquel país que sufra el problema al que el programa responde, sea cual sea; no hay por tanto en el anuncio discriminación alguna ${ }^{24}$. Por otro lado, la igualdad de trato obliga a tratar igual a los iguales, y desigualmente a los desiguales; el objeto de un programa OMT es atender precisamente a los desiguales: cuando se producen disrupciones, volatilidades, movimientos no siempre racionales de las agencias de notación, las intervenciones puntuales son necesarias precisamente en los mercados donde ello ocurre.

En segundo lugar y respecto a la prohibición de la financiación monetaria, los comentarios del TCFA en su auto de remisión de la cuestión prejudicial se detallan a continuación. Con relación al art. 123 TFUE, dice el TCFA en su recurso prejudicial —usando los razonamientos de la sentencia Pringle - que "[la decisión OMT] aparece también como incompatible con la prohibición de financiación monetaria del sector público, establecida en el art. 123 TFUE». Tiene — TCFA dixit_ no la finalidad monetaria que el BCE sostiene, sino una finalidad presupuestaria: «La Decisión OMT tiene por finalidad la neutralización de las primas de riesgo de los bonos gubernamentales de ciertos Estados miembros del área del euro, generadas por los mercados, y que afectan negativamente a la financiación de dichos Estados». Niega el TCFA el fundamento del programa OMT alegada por el BCE en su anuncio: la finalidad de pura política monetaria de conseguir que las volátiles y anómalas primas de los mercados mayoristas de deuda pública — principalmente de repos- no interfiriesen excesivamente en el nivel de los precios. En esta

23 Traducción del autor.

24 Es similar a cuando se adoptan en la PAC medidas sobre el vino, la remolacha o la pesca: su aplicación se circunscribe a países vinícolas, azucareros o pesqueros, y no a los demás, por lo que en principio podría hablarse de discriminación según el simplista razonamiento del TFCA, al privilegiarse a un país sobre otro. 
apreciación, adolece el TCFA del defecto de indicar al TFUE por dónde resolver las cuestiones prejudiciales, apoyándose en el peritaje del Bundesbank ante el TCFA, representado por su gobernador (único opositor dentro del Consejo de Gobierno del BCE al programa OMT).

\section{OFRECIMIENTO SIMULTÁNEO DE UN COMPROMISO POR EL TCFA AL TJUE}

Tras exponer largamente las razones que justificarían una respuesta del TJUE desfavorable al BCE, el TCFA apunta a una posible solución de compromiso para que el TJUE la considere. En efecto, al final del escrito de sumisión de la cuestión prejudicial, el TCFA le describe al TJUE las condiciones bajo las cuales el programa OMT sería compatible con el Derecho de la UE:

\subsection{Prohibición de la financiación monetaria}

Propone el TCFA que el BCE mantenga, al intervenir en el mercado de bonos, un "preferred creditor status", renunciando con ello al trato pari passu con otros titulares de deuda pública de un país bajo programa OMT, para evitar así que le afecte al Eurosistema el supuesto de un recorte unilateral o pactado de deuda, ya que de otro modo habría financiación monetaria prohibida. La contraindicación a esta sugerencia es que bajo un programa OMT, el Eurosistema entrará en el mercado secundario como un interviniente más, comprando bonos iguales y fungibles con los de los inversores privados; un estatuto de "preferred creditor status» para el Eurosistema cuando este actúa ex more privatorum en un mercado no responde a las prácticas actuales. Solamente en los mercados de préstamo - no de capitales - las instituciones financieras internacionales de estatuto público como el FMI, BIRD, BERD, BEI y otros bancos públicos de desarrollo, tienen reconocido generalmente su «preferred creditor status». Reconocer un «preferred creditor status» para carteras de bonos adquiridas por el Eurosistema en el mercado, produciría inmediatamente un encarecimiento y otras disfunciones en dicho mercado, regidos por el principio general de fungibilidad de los bonos, además de alegaciones de privilegio y discriminación a favor del Eurosistema.

\subsection{Límite cuantitativo ex-ante}

Otra condición que según el TCFA haría al programa OMT compatible con el estatuto del BCE, sería el establecimiento ex-ante por el BCE de un límite cuantitativo a sus intervenciones en el mercado de bonos soberanos, para recalcar su carácter de medida de apoyo a las adoptadas por el MEDE. Error 
de bulto del TCFA: aunque naturalmente en cualquier decisión de activar ese programa el Consejo de Gobierno del BCE consignará entre otras cosas, lógicamente, los niveles de intervención, el hecho de mantener secreto dicho nivel es condición sine qua non para el éxito del programa. Con el mero anuncio de una intervención, los mercados reaccionan en manada, por lo que la cuantía máxima no opera aquí como determinante, sino más bien al contrario: si se hace pública una cuantía máxima, precisamente se daría pie a los mercados para confiar en ella, mientras que si se mantiene secreta, el mero anuncio provocara un alineamiento del mercado.

\subsection{Alejamiento del mercado primario de deuda pública}

Otra condición que pone el TCFA para la compatibilidad con el derecho la UE del programa OMT, es que las intervenciones se hagan con un distanciamiento temporal respecto de las fechas de emisión: solo debe adquirirse deuda pública emitida y colocada ya en el mercado durante un tiempo, para asegurar que se trata de mercado secundario. El BCE en su anuncio dejó claro que operaría solo en el mercado secundario. Dos preguntas cabe hacerse. Una, :por qué un tribunal tiene que entrometerse en un aspecto operacional que material y formalmente corresponde a una institución que es, al mismo tiempo, la formalmente competente, la experta materialmente, y la que arriesga en su inversión? Parece — con todos los respetos- un activismo judicial inadecuado. $\mathrm{Y}$ dos, ¿̨no es esta sugerencia una prueba de que el TCFA se ha precipitado en admitir el recurso contra un programa que todavía requiere actos subsiguientes de ejecución?

El TCFA pone, además, un límite a los compromisos sugeridos al TJUE: que no se atente al carácter del Parlamento alemán como «dueño de las finanzas públicas germanas», carácter que considera parte del núcleo de identidad constitucional alemana que ni el derecho de la UE ni el TJUE pueden cambiar. En su recurso prejudicial, el TCFA advierte al TJUE que, diga lo que diga, tomará su propia decisión, anunciando que no planteará más recursos prejudiciales al TJUE sobre ello. Dice así el TCFA:

En el momento actual, no cabe predecir si, mediante la activación concreta de la Decisión OMT, y en relación con potenciales pérdidas para el Bundesbank con consecuencias para el presupuesto federal, podrían suscitarse cuestiones sobre la autonomía presupuestaria del Bundestag afectantes art. 9.3 de la Constitución alemana. Si fuera necesario, el TCFA tendría que examinar este aspecto, sobre la base de la interpretación del TJUE de la Decisión OMT, sin que proceda plantear una nueva cuestión prejudicial, y resolver sobre la inaplicación en Alemania del acto del BCE activando la Decisión OMT, ya que la evaluación del mantenimiento del 
núcleo identitario constitucional no debe de hacerse en base al derecho de la Unión sino, exclusivamente, en base al derecho constitucional alemán.

En definitiva, el TCFA anuncia al TJUE que decidirá sobre la participación del Bundesbank en un futurible programa OMT en base al riesgo de pérdidas para el presupuesto federal alemán. Lo que suscita algunas preguntas sin fácil respuesta: ¿¿deberá el BCE pedir autorización al Bundestag alemán para que el Bundesbank participe en un programa OMT? ¿En ese caso, quid de los otros parlamentos nacionales de la zona euro? ¿Deberá por idéntica lógica el BCE pedir permiso al Bundestag para toda operación del Eurosistema que conlleve riesgos para el Bundesbank y, por tanto, para el presupuesto de ingresos alemán? ¿Cómo se compatibiliza todo ello con el requisito fundamental de independencia del $\mathrm{BCE}$, una de las piedras clave que el propio TCFA exigió para autorizar la ratificación alemana del Tratado de Maastricht, el de Lisboa, y el pase de Alemania a la tercera fase de la UEM? ¿O debe el BCE tomar solo medidas que no conlleven nunca un riesgo?

\section{VOTOS PARTICULARES DEL RECURSO PREJUDICIAL}

La decisión del TCFA, de 14 enero 2014, de someter cuestiones prejudiciales al TJUE, primera en su historia a pesar de la clara obligación que establece el art. 267 TFUE a ese respecto, no ha sido unánime. Dos votos particulares dan luz sobre lo que han debido ser las discusiones habidas en la Sala Segunda del TCFA.

El primer voto particular es el del juez Lübbe-Wolff. Sostiene ese magistrado que hay aquí un exceso de jurisdicción y de activismo judicial por parte del TCFA. Identifica tres grandes razones al respecto:

- Que la jurisdicción competente para revisar los actos del BCE es el TJUE. No solo formalmente, sino porque el efecto de una decisión judicial negativa no se limita a Alemania, sino que afecta a toda la zona euro, y si conllevase la disolución del euro es impropio que sea el resultado de un tribunal nacional aplicando su derecho nacional.

- Que el criterio de admisibilidad de los recursos se ha flexibilizado tanto para admitir esta demanda que hace posible que cualquiera recurra un acto de una institución de la UE ante el TCFA alegando vagamente violación del «núcleo de identidad constitucional», como el principio democrático, violación de otros preceptos del derecho de la UE, o inacción gubernamental.

- La demanda se presenta contra el Gobierno y el Parlamento alemán, alegando inacción ante la Decisión OMT. Señala el juez Lübbe-Wolff 
que no es posible determinar qué tipo de acción deberían emprender el Bundestag o el Gobierno si el TCFA determinara finalmente que el programa OMT es ultra vires. Las demandas por inacción solo deben ser admisibles cuando una norma impone a la autoridad correspondiente un deber específico de actuar. En este caso no se vislumbra en los textos legales qué acción están obligados a tomar, y ha sido omitida ilegítimamente, por parte del Gobierno o Parlamento alemanes.

El segundo voto particular es del juez Gerhardt. Sostiene claramente la inadmisibilidad del recurso ante el TCFA por dos motivos:

- una sentencia preventiva no es procedente cuando el proceso de decisión no ha concluido y no hay aún acto jurídico impugnable, provocando una intervención del TCFA en el debate en curso acerca de la medida que adoptar. Los recurrentes deberían haber llevado a las instituciones políticas - Gobierno y Parlamento- las cuestiones que plantean, como la defensa del principio democrático, en vez de acudir directamente ante el TCFA, máxime cuando los representantes de Bundestag y Gobierno en el TCFA no coinciden con las ideas de los demandantes. Además, choca con el sistema europeo de protección judicial, en el que una acción preventiva es inadmisible y toda fiscalización judicial requiere la existencia de un acto.

- La cuestión de ultra vires planteada se refiere a una decisión del BCE que tiene aspectos de política monetaria y de política económica; el TCFA no está capacitado para asegurar que hay ultra vires en este tipo de decisiones complejas, máxime antes de tener delante un acto jurídico concreto.

\section{LAS CONCLUSIONES DEL ABOGADO GENERAL DEL TJUE}

El abogado general (AG) del TJUE ${ }^{25}$ pronunció sus conclusiones el 14 enero 2015, de 62 páginas de extensión. En ellas, tras la descripción de la cuestión litigiosa, muestra cierta perplejidad acerca de las características del recurso prejudicial, en particular:

- que el TCFA parta de su constatación de que el programa OMT es una actuación ultra vires del $\mathrm{BCE}^{26}$, lo que es precisamente el objeto del recurso prejudicial;

25 Pedro Cruz Villalón.

26 Punto 43. 
- que el TCFA no se considere vinculado por la sentencia que en la fase prejudicial dicte el TJUE, sino que pueda aquel a posteriori ejercer un control de lo que el TJUE sentencie.

Dice el AG que es de aplicación a los recursos prejudiciales el principio de «cooperación leal» entre Estados miembros e instituciones de la UE, recogido en el art. 4 TUE, también contenido en alguna sentencia del TCFA como obligación de europarechtsfreundlichkeit ${ }^{27}$, y llega el AG a afirmar que la consideración por el TCFA de que una sentencia del TJUE en vía prejudicial es un mero "pronunciamiento previo» (distinto a un pronunciamiento final que haría el TCFA reservándose el derecho a desviarse de la sentencia del TJUE si ésta afectara a los derechos básicos de los alemanes) consumaría «una ruptura del pacto constitucional que subyace en la integración europea» ${ }^{28}$. Como vía de salida a dicho potencial conflicto, el AG alude a que la UE se fundamenta en "tradiciones constitucionales comunes», que la UE conlleva una comunidad no solo de Derecho sino «de cultura constitucional, parte de la identidad común de la Unión», con «la importante consecuencia de que la identidad constitucional de cada Estado miembro no puede ser contraria a dicha identidad común», debiendo así «inspirar una confluencia básica entre la identidad constitucional de la Unión y la de cada uno de los Estados miembros ${ }^{29}$. Concluye el AG deseando que la sentencia final del TCFA no contenga "conclusiones en abierta contradicción con la respuesta del TJUE»" ${ }^{30}$.

Y por otro lado, el AG recomienda al TJUE no entrar en todo cuanto le plantea el TCFA, sino que se centre en dar respuesta a las cuestiones jurídicas de fondo planteadas, ignorando «la suerte final de su respuesta» por parte del $\mathrm{TCFA}^{31}$, confiando en que este "asumirá como suficiente y definitiva» la sentencia del TJUE ${ }^{32}$.

En cuanto a la admisibilidad de un recurso prejudicial contra un mero anuncio del BCE, el AG opina que, aunque no sea formalmente un acto jurídico, por sus efectos en el mercado debe considerarse "con un enfoque antiformalista» como si de un acto jurídico se tratase, de conformidad con alguna jurisprudencia del TJUE. De otro modo — dice— «se corre el riesgo de que una institución disfrace actos con vocación hacia el exterior como

\footnotetext{
27 Literalmente «amistad con el derecho europeo».

28 Punto 52

29 Punto 61

30 Punto 63.

31 Punto 66.

32 Punto 67.
} 
programas generales». Y justifica la admisibilidad como acto impugnable en que a) tuvo discusión larga en el BCE; b) se publicaron sus características básicas, que obligan al Eurosistema; c) los bancos centrales influyen en los mercados con su comunicación pública, sin necesidad de actos jurídicos, y d) el anuncio tuvo efectos inmediatos en los mercados, y que perduraban hasta el día de las conclusiones del AG.

Con relación a las cuestiones planteadas por el TCFA al TJUE, las conclusiones del AG pueden resumirse así:

\section{Si el programa OMT es «política monetaria» (permitido al BCE) o «política fiscal y económica» (ultra vires para el BCE)}

El AG considera a) que el BCE tiene un amplio margen de apreciación en el diseño y ejecución de la política monetaria, y dispone de mayor capacidad técnica que la Justicia para su aplicación, por lo que la Justicia tiene que tener «un considerable grado de contención»; b) que el art. 18 del Estatuto del BCE le faculta expresa y específicamente para «operar en los mercados financieros comprando y vendiendo valores», y c) que varios bancos centrales del planeta han usado intervenciones en los mercados para su política monetaria, en particular en la última crisis financiera.

El AG tiene dificultades con la vinculación del programa OMT con la condición de que el MEDE adopte un programa de asistencia que incluya posibles compras directas de deuda soberana, ya que ello vincula lo «monetario» con las «políticas económica y fiscal»; y la solución la encuentra el AG en proponer que el BCE deje de formar parte de las troicas que preparan los programas de asistencia a los Estados con desequilibrios, y mantenga una distancia funcional entre los programas del MEDE y del BCE.

El AG expresa — como el TCFA— ciertas dificultades acerca del respeto por el programa OMT del principio de proporcionalidad, ya que el anuncio del BCE no lo justifica, y pide que en su activación el BCE motive su decisión, asegurando su adecuación a la situación que se trate de corregir y su necesidad. Sin embargo, a la vista de los efectos del mero anuncio del programa - una reducción generalizada de los tipos de interés de bonos soberanos- lo considera «medida adecuada», y deja al momento de la activación del programa la verificación del test de necesidad y proporcionalidad.

Finalmente, el AG considera «no concluyente» la alegación del TCFA de que el carácter selectivo del programa OMT, al aplicarse a uno o pocos Estados pero no a todos los de la zona monetaria, lo caracteriza como «política económica» más que como "política monetaria». El argumento del AG es que el objetivo del programa es restablecer la correcta transmisión de los impulsos 
monetarios en toda el área monetaria, lo que no impide intervenciones selectivas en algunos de ellos, donde se localiza el problema que afecta a todos.

\section{Sobre la compatibilidad del programa OMT con la prohibición estatutaria de financiación monetaria al sector público}

El AG en sus conclusiones hace un análisis histórico y económico del art. 123 TFUE, que contiene la prohibición al Eurosistema de financiar monetariamente al sector público. Y observa que incurren en la prohibición las compras en el mercado primario, esto es, directamente del Tesoro emisor, pero no las operaciones en el mercado secundario, que operan libremente sobre títulos que ya se adquirieron por otro, y que son las que afectan a su nivel de precios y por tanto al canal de transmisión de la política monetaria. El AG señala también que, como ya lo hace la legislación de desarrollo del art. $123^{33}$, este prohíbe las operaciones en el mercado secundario cuyo efecto sea eludir la prohibición del precepto.

\section{LA ADOPCIÓN DE UN PROGRAMA DE COMPRA DE VALORES PÚBLICOS POR EL BCE}

Pocos días después de las conclusiones del AG, el 22 de enero 2015 el presidente del BCE, Sr. Draghi, anunció la decisión del Consejo de Gobierno del BCE de poner en marcha un programa de compras masivas de activos financieros públicos por parte del Eurosistema, por importes de $60000 \mathrm{mi}$ llones de euros mensuales (Aditional Asset Purchase Programme o APP ${ }^{34}$ ), emitidos por administraciones centrales de los Estados del euro y por entidades públicas europeas. Su finalidad era evitar la deflación una vez que los intereses han marcado su nivel más bajo y de llevar la inflación de la zona monetaria al objetivo del BCE de "cerca de, pero inferior a, un 2\% anual». Sigue con ello el BCE el modelo del quantitative easing de la Reserva Federal americana y del Bank of England. Se completaba así el programa de compras de bonos privados

33 Reglamento (CE) 3603/93 del Consejo, de 13 de diciembre de 1993, por el que se establecen definiciones para la aplicación de las prohibiciones a que se refieren el art. 104 y el apdo. 1 del art. 104 B del Tratado (DO L 332 de 31.12.1993, p. 1).

34 En septiembre 2016 la inversión total del Eurosistema en los programas de QE ascendía 1305942 millones de euros, de los que un $85 \%$ son bonos soberanos. Ver síntesis del programa APP en: https://www.ecb.europa.eu/explainers/tell-me-more/ html/asset-purchase.es.html 
(cédulas hipotecarias y titulizaciones) por parte del Eurosistema, puesto en marcha el 4 de septiembre 2014.

Dos meses más tarde, en marzo de 2015, el BCE aprobó la norma reguladora de este nuevo instrumento de política monetaria ${ }^{35}$. La base legal para el programa APP es el art. 18.1 del Estatuto del SEBC, la misma que la prevista para el programa OMT si este se hubiera puesto en práctica. En su preámbulo dice expresamente el BCE que el APP «cumple plenamente con las obligaciones de los bancos centrales del Eurosistema con arreglo a los Tratados, incluida la prohibición de financiación monetaria, y no impide el funcionamiento del Eurosistema de conformidad con el principio de una economía de mercado abierta y con libre competencia.» Y dice también que «acepta el mismo tratamiento (pari passu) que los inversores privados en lo relativo a los instrumentos de renta fija negociables que el Eurosistema pueda comprar de conformidad con los términos de dichos instrumentos»; es decir, nada del preferred creditor status demandado por el TCFA al TJUE en su recurso prejudicial como solución de compromiso para aceptar el veredicto de este. La norma prevé tan solo compras en los mercados secundarios y previo un lapso de tiempo desde la emisión de los títulos que permita la formación de un precio de mercado. En cuanto a los bonos soberanos de los países bajo un programa MEDE, se condiciona su adquisición por parte del Eurosistema a que dichos países reciban un informe favorable de la UE (y del FMI en el caso de que este hubiera concedido su ayuda condicional al país en cuestión).

En marzo 2016, el BCE amplió el volumen de las compras de dichos activos por el Eurosistema a 80000 millones de euros mensuales. El APP estará en vigor hasta marzo 2017, si bien el BCE ha señalado que podrá prorrogarse en la medida necesaria.

Existe una gran coincidencia entre el programa OMT de intervención en el mercado de bonos soberanos de países en crisis, y el programa APP de compras de activos públicos lanzado por el BCE en marzo 2015. En efecto, el importe de dicho programa APP ya supone el $85 \%$ de los activos totales, privados y públicos, adquiridos por el Eurosistema. Y los riesgos para el Eurosistema son aquí muy superiores al caso de una activación de un programa OMT limitado a uno o pocos países.

Un año y medio desde su aplicación, el APP ha producido el alineamiento de los diferenciales de los bonos soberanos y reducido la fragmentación de la zona monetaria. Aun cuando la opinión pública alemana es más bien negativa

35 Decisión (UE) 2015/774 del Banco Central Europeo, de 4 de marzo de 2015, sobre un programa de compras de valores públicos en mercados secundarios (DO L 121, de 14 de mayo de 2015, p.20). 
acerca de este nuevo instrumento de política monetaria del Eurosistema, lo cierto - y relevante aquí- es que a septiembre 2016, más de año y medio desde su puesta en marcha, no ha habido recursos judiciales contra el mismo, ni en Alemania ni ante el TJUE. Y el Bundesbank participa con normalidad en dichos programas en la proporción que le corresponde, como todos los bancos centrales del Eurosistema.

\section{LA SENTENCIA DEL TJUE EN VÍA PREJUDICIAL}

El 16 junio 2015 la Gran Sala del TJUE dictó sentencia ${ }^{36}$ respondiendo a las preguntas formuladas en el recurso prejudicial del TCFA. El alto tribunal europeo motiva y dictamina en su resolución que

los arts. 119 TFUE, 123 TFUE, apdo. 1, y 127 TFUE, apdos. 1 y 2, así como los arts. 17 a 24 del Protocolo (núm. 4) sobre los Estatutos del Sistema Europeo de Bancos Centrales y del Banco Central Europeo, deben interpretarse en el sentido de que autorizan al Sistema Europeo de Bancos Centrales (SEBC) a adoptar un programa de compra de bonos soberanos en los mercados secundarios como el que se anunció en el comunicado de prensa al que se hace referencia en el acta de la reunión núm. 340 del Consejo de Gobierno del Banco Central Europeo (BCE) de 5 y 6 de septiembre de 2012.

El TJUE sigue en su sentencia las recomendaciones del AG de centrarse en las cuestiones de fondo planteadas por el TCFA, sin entrar en valorar las posiciones previas de este, procesales y sustantivas, ni su oferta de soluciones de compromiso, ni la reserva explícita de un pretendido derecho a no respetar la sentencia que dicte el TJUE, lo que explica un fallo relativamente corto, claro y tajante (en 23 páginas).

Siete gobiernos nacionales, más la Comisión, el Parlamento y el BCE, entraron en las cuestiones procesales suscitadas y solicitaron en la vista oral la inadmisibilidad del recurso prejudicial, derivada de la inadmisibilidad del recurso constitucional que debió declararse ad limina por el TCFA al tratar de juzgarse en un tribunal nacional la licitud y validez de un acto de una institución europea como es el $\mathrm{BCE}$, máxime si era un acto preparatorio, mero anuncio programático. El TJUE rechaza en su sentencia dichas pretensiones de inadmisibilidad con el argumento de que la admisibilidad o inadmisibilidad de un recurso planteado ante una jurisdicción nacional corresponde en

36 Sentencia del Tribunal de Justicia (Gran Sala) de 16 de junio de 2015, Gawweiler y otros (C-62/14, EU:C:2015:400). 
exclusiva a dicha jurisdicción nacional. Según el TJUE, una cuestión prejudicial relativa a un recurso admitido a trámite en sede nacional, goza de presunción de pertinencia si solicita una interpretación auténtica del derecho de la UE. Por lo que se refiere a la reserva expresa hecha por el TCFA de su derecho a no cumplir la sentencia que dicte el TJUE en vía prejudicial, guarda este total — aunque elocuente- silencio.

De conformidad con la jurisprudencia del TJUE sobre cuestiones prejudiciales, ${ }^{37}$ el TJUE se centra en contestar las cuestiones de fondo, que - resumidamente, y en línea con las Conclusiones del AG— hace así:

\section{Acerca de si el programa OMT es ultra vires, al tratarse de «política económica» y no de «política monetaria»}

El TJUE dice que el TFUE define los «objetivos» y los «medios» de la política monetaria atribuida al $\mathrm{BCE}$, y valora razonada y positivamente que el programa OMT responde al objetivo de estabilidad de precios, y que los medios a emplear, compra y venta de bonos en el mercado secundario, son conformes con los instrumentos puestos a disposición por el TFUE, en particular, en el art. 18 del Estatuto del BCE. Admite que el programa OMT puede contribuir a la estabilidad del euro y de las finanzas del Estado emisor, pero no por ello pertenece al ámbito de la política económica — competencia de los Estados y de la UE - sino que se corresponde con la competencia estatutaria del BCE, de apoyar la política económica de la UE.

Analiza también si el programa OMT respeta el principio de «proporcionalidad» requerido por el art. 4 del TUE, reconociendo — en línea con su jurisprudencia consolidada - que las instituciones de la UE, entre ellas el BCE, disponen de una «amplia facultad de apreciación» de todas las circunstancias pertinentes para la adopción de políticas y actos, no pudiendo los tribunales sustituirse a las instituciones sino bajo el prisma del respeto a la legalidad.

En este caso concreto, el TJUE considera que para adoptar dicho programa el «BCE se basó en un análisis de la zona euro» que mostraba «una gran volatilidad y unas divergencias extremadamente importantes», y que ello «fragilizó en gran medida el mecanismo de transmisión de la política

37 Véase por todas la Sentencia del TJUE de 12 septiembre 2013: «Corresponde al TJUE en el marco del procedimiento de cooperación con los órganos jurisdiccionales nacionales establecido por el art. 267 del TFUE, proporcionar al órgano jurisdiccional una respuesta útil que le permita dirimir el litigio que conoce». Y en la Sentencia del TJUE del 8 septiembre 2015: «Cuando las cuestiones planteadas se refieran a la interpretación del derecho de la UE, el TJUE estará, en principio, obligado a pronunciarse.» 
monetaria dando lugar a una fragmentación de las condiciones de refinanciación de los bancos y de los costes del crédito». Concluye el TJUE de lo anterior que el $\mathrm{BCE}$ «podía considerar legítimamente que [el programa OMT] era idóneo para mantener la estabilidad de los precios».

Observa el TJUE que la propia condicionalidad y salvaguardias del programa OMT se desprende ya de su anuncio en septiembre 2012, que circunscribe y limita su ulterior aplicación por el BCE, en particular por la específica condición de que exista previamente un programa del MEDE imponiendo medidas de saneamiento de las finanzas públicas del Estado miembro en cuestión. El TJUE rechaza la condición exigida por el TCFA de que la activación del programa OMT requiera una limitación cuantitativa ex ante, ya que ello perjudicaría su eficacia ante los mercados.

Y señala finalmente que la aplicación eventual del programa requiere una nueva apreciación específica de la situación por parte del Consejo de Gobierno del $\mathrm{BCE}$, y que «más de dos años después del anuncio del programa, sigue sin llevarse a cabo al haber considerado el Consejo de Gobierno que la situación económica de la zona euro no justificaba aplicarlo.»

\section{Acerca de si el programa OMT vulnera la prohibición de financiación monetaria por el Eurosistema}

El art. 123 TFUE prohíbe a los bancos centrales financiar al sector público de los Estados miembros ${ }^{38}$. El TCFA consultaba sobre si el programa OMT violaba el precepto, manifestando previamente su opinión afirmativa, y ofreciendo otra opinión permisiva sujeto a que el Eurosistema se reservase al operar en los mercados la condición de preferred creditor status.

El TJUE rechaza la posición del TCFA. La finalidad de dicha prohibición es que los Estados que adoptaron el euro mantengan «una sana política presupuestaria». La condición de previa existencia de un programa del MEDE indica que el Estado emisor queda obligado a sanear su política presupuestaria. El propio condicionado contenido en el anuncio del programa OMT, que permite suspender las intervenciones en todo momento y revender los bonos adquiridos, incentiva la adopción de medidas de saneamiento fiscal, pues su incumplimiento motivaría la terminación de las intervenciones OMT. Finalmente, alude el TJUE al compromiso del BCE — parte del anuncio del

38 Con la única excepción del Reino Unido, ya que en su Protocolo específico (núm. 15 del TFUE) se permite al Banco de Inglaterra — mientras no adopte el euro- mantener la línea de tesorería a corto plazo a su Gobierno denominada tradicionalmente Ways and Means Facility. 
programa - de evitar que las intervenciones del Eurosistema en los mercados secundarios produzcan un efecto equivalente a la compra de bonos soberanos en el mercado primario.

En cuanto a la condición de preferred creditor status que exige el TCFA para evitar el efecto de financiación monetaria, la rechaza el TJUE basándose en los argumentos del BCE: en este tipo de intervenciones el BCE opera según las reglas del mercado y no como inversor privilegiado, pues ello crearía disrupciones en dicho mercado. Y el art. 18 del Estatuto del BCE no establece que deba actuar en los mercados como actor privilegiado, sino asumiendo los riesgos propios de todo operador.

El TJUE reconoce que el invertir en bonos soberanos de países en dificultad presupuestaria «expone al $\mathrm{BCE}$ al riesgo de sufrir pérdidas importantes», pero señala acertadamente que todas las operaciones de mercado abierto de los bancos centrales conllevan riesgos; y que precisamente las condiciones del programa OMT «son idóneas para reducir el riesgo de pérdidas al que se expone el BCE».

Finalmente, en relación con la alegación de «selectividad» del programa OMT, el TJUE se alinea también con las conclusiones del AG, en el sentido de que, si bien las intervenciones pueden ser selectivas, el objetivo de ellas concierne a la totalidad de la zona monetaria, y razona — además- que no tendría sentido imponer al BCE que ampliara su programa a todos los Estados del euro, «más allá de lo necesario para alcanzar sus objetivos».

\section{LA SENTENCIA FINAL DEL TCFA}

El 21 junio 2016, justo un año después de la sentencia del TJUE en vía prejudicial, el TCFA dictó sentencia en el pleito constitucional. El contenido de sus 30 páginas de extensión y de sus 220 considerandos puede resumirse así:

\section{Primero}

En línea con sus sentencias anteriores en relación con el Tratado de Maastricht y la UEM, declara que los poderes básicos otorgados por los ciudadanos al Parlamento y Gobierno alemanes no pueden vaciarse de contenido por las instituciones europeas más allá de lo previsto por los Tratados UE. En consecuencia, toda decisión de las instituciones, agencias y organismos de la UE solo son válidas en Alemania si respetan los derechos democráticos reconocidos a los ciudadanos en la LFA. De ahí que: a) toda decisión de dichas entidades que sean calificadas de ultra vires son susceptibles de violar dichos 
derechos, y b) las instituciones constitucionales de Alemania deben oponerse, política y jurídicamente, a aquellas decisiones de los órganos de la UE que sean «manifiestamente» ultra vires y afecten al núcleo de la identidad constitucional alemana, y, en general, proteger y promover el respeto a los derechos democráticos de los ciudadanos.

\section{Segundo}

En línea con la sentencia del TJUE de junio 2015, considera el TCFA que el programa OMT sí cumple con las condiciones establecidas por el BCE en su sentencia prejudicial, esto es: a) no excede «manifiestamente» los poderes que el TFUE atribuye al BCE y Eurosistema; b) no presenta una amenaza constitucionalmente relevante a los derechos de decisión presupuestaria del Parlamento y Gobierno alemanes; c) la ausencia de reclamación contra el programa OMT ante el TJUE por parte del Gobierno o del Parlamento alemanes no viola los derechos democráticos de los ciudadanos alemanes, y d) es inadmisible la demanda ante el TCFA por parte de particulares impugnando actos de una institución europea.

\section{Tercero}

En el caso de que el BCE decidiera desarrollar un programa OMT, el Bundesbank solo podrá ejecutarlo si la decisión del BCE cumple con las condiciones señaladas por el TJUE para que no exista una situación de ultra vires, que resumidamente son las condiciones siguientes:

- que los bonos para adquirir tengan acceso a los mercados, y que haya un período de tiempo entre la emisión de los títulos y su colocación en el mercado, y el comienzo de compras por el Eurosistema;

- que la adquisición de los bonos por el Eurosistema no sea hecha normalmente "a término", sino para ser revendida en el mercado antes de su vencimiento y en cuanto sea posible;

- que no se anuncien ex-ante las intervenciones concretas, pero también que estas no sean intervenciones sin límites preestablecidos por el BCE.

El TCFA acepta que el TJUE está en su pleno y exclusivo derecho de determinar cuándo y en qué condiciones no existe un manifiesto ultra vires en los actos de las instituciones europeas, al ser ello de su exclusiva competencia según los Tratados UE. Pero el TCFA, aunque acepta la sentencia del TJUE de 16 junio de 2015, no puede dejar sin explicitar en sus considerandos los 
defectos que encuentra en dicha sentencia europea, principalmente los dos siguientes:

- que el TJUE es simplista en la categorización del programa OMT como "política monetaria» y no valora críticamente los argumentos que apoyan su efecto en la "política económica» de los Estados, por lo que tiene al menos una naturaleza mixta, monetaria y económica;

- que el TJUE no aplica una interpretación restrictiva a los poderes conferidos por el TFUE al BCE, que - a su juicio- es necesaria al tratarse de una institución no democrática.

Y deja «bien atado» el cumplimiento de su sentencia al establecer que, aunque ni el Parlamento ni el Gobierno alemanes tengan una obligación de actuar contra el programa OMT, al no ser manifiestamente ultra vires, les impone la obligación de monitorizar activamente cualquier ejecución de dicho programa, con objeto de asegurar el cumplimiento de las condiciones establecidas por el TJUE para no calificar de manifiestamente ultra vires el programa OMT. Además, el Bundesbank solo puede participar en un programa OMT en la medida en que sus condiciones incluyan las definidas por el TJUE para asegurar su compatibilidad con el Tratado. Sobre este último apartado ver más abajo en las conclusiones de este resumen.

\section{ALGUNAS CONCLUSIONES}

a) Como resumen crítico de cuanto antecede, puede decirse como preámbulo que estamos ante un caso politizado, objeto de controversia pública, especialmente en Alemania, donde un segmento de la población más o menos importante, crítico con el euro, y con apoyo de ciertos medios influyentes de comunicación social y de algunos institutos académicos, mantiene una línea hipercrítica y restrictiva respecto de las instituciones europeas, y para ello utiliza el acceso directo al TCFA, más sencillo que ante el TJUE. En efecto, el TJUE requiere unos requisitos de legitimación para recurrir más restrictivos que los que pide el TCFA, así como la existencia de un acto productor de efectos jurídicos, que el TCFA parece no exigir adentrándose en el examen de meras situaciones preliminares, programas de concreción todavía distante.

Las razones que motivaron la adopción del programa OMT del BCE han quedado de hecho confirmadas a posteriori con la evolución y situación de los mercados tras el anuncio del BCE en septiembre 2012: sin necesidad de activar el programa, las increíbles y volátiles primas de riesgo del 2011-2012 han regresado a niveles más razonables y su volatilidad ha disminuido; quienes 
apostaron por la disolución del euro perdieron su dinero. Por otro lado, el balance diario del sistema Target2 del BCE para con los bancos centrales del Eurosistema - que mide los movimientos de masas dinerarias dentro de la zona monetaria - está volviendo también a niveles precrisis. La adopción en 2015 por el BCE del programa APP de compras masivas de bonos soberanos, ha sido la puntilla para quienes se opusieron beligerantemente al anuncio del programa OMT, máxime ante la ausencia de impugnaciones contra el nuevo programa APP. Buenas noticias para el euro, y menos alarmismo e intranquilidad en los sectores populistas alemanes.

b) Siendo la primera vez, y por ahora única, que el TCFA cumple lo dispuesto en el art. 267 TFUE, hay que felicitarse de que este precepto haya entrado por fin - seis décadas tras la ratificación alemana del Tratado de Roma- en la agenda del TCFA y abierto el diálogo judicial entre las dos jurisdicciones, aunque pueda todavía observarse en los escritos del TCFA cierta tensión latente - y desconfianza insana - entre ambas. Bueno por tanto este paso procesal para Europa; bueno para la europarechtsfreundlichkeit, defendido por la doctrina, bueno también para el principio de «cooperación leal» en el que se basa la construcción europea ${ }^{39}$, así como para la pujante corriente de opinión que sostiene un criterio de identidad constitucional básica y común a todos los Estados miembros, bajo los cuales deben operar las jurisdicciones nacionales en beneficio de la seguridad jurídica. No obstante, merece rechazo el modo empleado por el TCFA para recurrir al TJUE: ausencia de neutralidad en su formulación, planteamiento de compromisos aceptables por el TCFA, y reserva del derecho a inaplicar la sentencia del TJUE.

c) Hubiera sido lógica por parte del TCFA la inadmisibilidad ad limina del recurso, ya que su construcción era sencillamente artificial, al tratarse de revisar un acto de una institución europea y no la inacción del Gobierno y Parlamento alemanes (que apenas dispusieron de tiempo material — seis días - para reaccionar al anuncio del programa OMT antes de que los demandantes presentaran su recurso ante el TCFA). Dicha astuta construcción dejó al que era el verdadero «demandado» — el BCE - fuera del proceso, sin legitimación pasiva: no fue parte procesal hasta la fase prejudicial ante el TJUE, no pudo defenderse en sede constitucional, ni influir en la redacción del recurso prejudicial; aberración impropia de un alto Tribunal que debe asegurar el derecho fundamental de defensa.

Curiosamente el propio TCFA recoge velas al final del largo proceso en este punto, y en su sentencia ${ }^{40}$ afirma una «inadmisibilidad parcial» carente

39 Art. 4 (3) TUE.

40 Párrafos 95 a 97. 
apenas de efectos, ya que pese a la misma entra a resolver el fondo de todas las cuestiones planteadas. Dicha inadmisibilidad parcial la aplica para los recursos de aquellos demandantes que cándidamente impugnaron directamente el programa OMT anunciado por el $\mathrm{BCE}^{41}$, pero no la aplica el TCFA a los demás demandantes que - más astutos - lo que contestan es la inactividad contenciosa del Gobierno y Parlamento alemanes ${ }^{42}$ (el anuncio OMT se hizo el 6 de septiembre 2012, y los recursos se presentan el 12 septiembre 2012: ¿cabe razonablemente pensar que el Gobierno y Parlamento alemanes hubieran podido iniciar una acción contra el BCE en el plazo de 6 días? ¿Qué ilegalidad cabe considerar aquí en su inacción? ¿Dónde está escrito que Gobierno y Parlamento deban recurrir ante el TJUE en un plazo tan breve que apenas permite una reflexión o discusión, interna o externa?)

d) Al mismo tiempo, la sentencia final del TCFA viene implícitamente a admitir su «precipitación» de haber admitido su competencia para juzgar un acto meramente programático —el anuncio del programa OMT_- al reconocer en su sentencia como esencial para juzgar si hay un ultra vires o no, el conocer las condiciones concretas que se contendrán en el acto jurídico futuro del BCE que disponga en su día la puesta en práctica del programa OMT. En efecto, es en la sentencia del TJUE de 16 junio 2015 donde se contienen los parámetros básicos que el BCE debería respetar para que sus intervenciones en el mercado de bonos soberanos (i) no se califiquen como financiación monetaria (prohibida), y (ii) sean proporcionales a la finalidad de corregir la volatilidad de las primas de riesgo (y por tanto se califiquen como «política monetaria», permisible). Dice el TCFA que dichas condiciones mencionadas por el TJUE en su sentencia hay que calificarlas como requisitos jurídicamente vinculantes (als rechtsverbindliche Kriterien ansieht) ${ }^{43}$. Más lógico hubiera sido inadmitir una demanda prematura contra el anuncio de un programa y deferir el juicio sobre él al acto o actos jurídicos de ejecución, disponiendo así en ese momento de todos los elementos de juicio. El lado positivo de esta prisa por juzgar está en informar así con antelación al BCE de los elementos que debe tener en cuenta si llega el momento de activar el programa OMT; prisa, por cierto, que se atenúa a medida en que el TCFA entra en el tema,

$41 \mathrm{Al}$ reconocerse que la impugnación de actos del BCE debe de hacerse en sede del TJUE.

42 Calificándose así el litigio como intraalemán (Organstreit), dentro de las competencias del TFCA.

43 La larga justificación de que, bajo ciertas condiciones — que habrán de recogerse en los actos futuros de ejecución del programa OMT - las intervenciones del Eurosistema son compatibles con el TFUE se encuentra en los párrafos 191 a 197 de la sentencia del TFCA. 
ya que finalmente transcurren cuatro años de proceso hasta la sentencia final, cuando el programa OMT ha dejado afortunadamente de ser necesario. Esta amplitud dada a la admisibilidad de la impugnación elimina el carácter «revisorio» de la jurisdicción y le hace partícipe de la propia elaboración del acto jurídico, obligando al BCE, en este caso, a no basar su decisión en sus propios trabajos preparatorios - $\mathrm{y}$, en definitiva, en su independencia-, sino en las consideraciones que anticipadamente se hayan hecho en sede judicial.

e) Quizá un último aspecto criticable de la sentencia del TCFA es la parte $3^{a}$ del fallo, en especial el párrafo 206, en el que el alto Tribunal impone al Bundesbank la prohibición de ejecutar una decisión del Consejo de Gobierno del BCE si - a su juicio particular- dicha decisión no cumple las condiciones establecidas por el TJUE en su sentencia del 16 junio 2015. Las citadas condiciones no son precisas, sino meramente conceptuales e indeterminadas ${ }^{44} ;$ y en su momento pueden aparecer necesarias otras, similares o parcialmente diferentes. La ausencia de una reglamentación jurídica de dichas «condiciones» no puede suplirse con una afirmación de que un obiter dictum del TJUE es «jurídicamente vinculante» ${ }^{45}$. Al deferir al solo juicio del Bundesbank la evaluación de si la decisión del BCE activando el programa cumple o no suficientemente dichas condiciones, se abre la vía para un posible resultado claramente antijurídico y dañino para la confianza general en el euro: que un solo miembro del Eurosistema —el Bundesbank — simplemente no participe en el programa OMT activado, al amparo del fallo del TCFA, o se sirva de él para imponer su criterio al Consejo de Gobierno del $\mathrm{BCE}^{46}$, único órgano de decisión del sistema.

Fundamento constitucional del Eurosistema es el funcionamiento por decisiones mayoritarias de su órgano de gobierno, y la subordinación de todos los bancos centrales del Eurosistema a dichas decisiones. Eso es puro

44 Por ejemplo, el volumen de las intervenciones tiene que ser «limitado» (¿cuánto?:60 000 millones de euros o 5000 millones?). Debe haber un plazo «mínimo» entre la emisión de bonos en el mercado primario y las compras por el Eurosistema en el mercado secundario ( 15 días, o 3 meses?). Los bonos adquiridos solo «excepcionalmente» se mantendrán a vencimiento (¿uno de cada tres?, ¿ uno de cada 20). Se suspenden las compras cuando las intervenciones sean «innecesarias» (¿cómo medir la innecesariedad?); etc.

45 Véase nota 43.

46 No hay que olvidar que la economía alemana es la más importante de la zona monetaria, y que el peso del Bundesbank dentro del Eurosistema es de un 25,72 \%. La activación de un programa OMT impondría al Bundesbank la obligación de invertir una cuarta parte del total programado (para el Banco de España la cantidad de compras sería del 12,60\%, aproximadamente la mitad que Alemania). 
derecho primario de la $\mathrm{UE}^{47}$, naturalmente bajo control judicial. El párrafo 206 de la sentencia del TCFA podría abrir brechas en un sistema institucional que ha venido funcionando satisfactoriamente, como lo muestra desde 2015 la pacífica participación del Bundesbank en el programa APP de compras masivas de bonos soberanos. No es misión de un tribunal nacional conceder licencia para la desobediencia civil, subversiva de un sistema - el Eurosistema - reglado en el derecho primario de la UE. Licencia, además, inconsistente con el propio fallo constitucional, pues ¿de qué sirve que el TCFA imponga a Gobierno y Parlamento alemanes una obligación especial de celosa vigilancia del programa OMT — lógicamente para impugnar cualquier desvío por el BCE - si puede el Bundesbank simplemente incumplir su obligación como parte del Eurosistema al amparo de lo que le indica el TCFA? ${ }^{48}$

f) La fase del proceso judicial a nivel europeo merece por el contrario una crítica muy favorable: las conclusiones del abogado general son conciliadoras y son prácticas, toda vez que apuntan acertadamente al camino a recorrer por el TJUE ante la difícil situación creada; y la sentencia del TJUE, concisa y clara, evita la confrontación con el TCFA, elude entrar en el juego de valorar los prejuicios del tribunal nacional recurrente, así como las fórmulas de compromiso que el TCFA le ofrece, ignora su amenaza de desobediencia al fallo, y se centra en lo esencial, que es responder a las preguntas que se le formulan. Tanto el AG como el TJUE facilitan así el buen final de un litigio mal planteado, fomentando constructivamente el diálogo de jurisdicciones y el respeto al régimen previsto para la vía prejudicial en el art. 267 TFUE.

g) Finalmente, hay que destacar y valorar positivamente —en medio de este largo proceso judicial en el que el BCE no es parte, pero cuyo objeto es condicionar precisamente su política monetaria—, la independencia del $\mathrm{BCE}$, un principio fundamental recogido en el derecho primario de la UE y exigido por el TCFA al juzgar sobre la UEM. Dicha independencia queda demostrada por el BCE al acordar — con anterioridad a la sentencia del TJUE y a la sentencia del TCFA— un programa masivo de compras de bonos soberanos

47 Art. 282 (2) TFUE.

48 Si comparamos la situación descrita con la del Sistema de la Reserva Federal americana, ¿cabe pensar en que el Federal Reserve Bank of New York incumpla una decisión del Federal Reserve Board of Governors de Washington, que es el órgano decisorio único para todo el Sistema de la Reserva Federal? ¿O en que un tribunal neoyorquino le autorice a dicho incumplimiento? ¿Qué efecto tendría una situación así en la confianza general en el sistema? 
(Aditional Asset Purchase Programme o $\mathrm{APP}^{49}$ ) puesto en ejecución por todo el Eurosistema en marzo 2015 — con inclusión de los países bajo programa de rescate- y en vigor hasta marzo 2017, que no ha sido impugnado ni contiene las condiciones que el TCFA quiere imponerle para el programa OMT. El BCE ha demostrado en este caso que tiene la independencia y capacidad para - como exigía Sir Walter Bagehot a un banco central en tiempos de crisis- "To lean against the wind $"^{50}$. Lo que nos lleva a unas reflexiones finales acerca de este largo pleito sobre el programa OMT, un programa mucho más limitado (muy pocos países destinatarios potenciales, más condicionado y de menores cuantías) que el programa APP, y nunca activado, ya que este ha cumplido la misión de aquel: ¿por qué nadie litigó contra el programa APP cuando este se anunció en enero 2015 o cuando se puso en marcha en marzo 2015? ¿Fue ese litigio intraalemán contra el anuncio por el BCE del programa OMT un pleito artificialmente — políticamente - creado por sectores de la sociedad alemana, críticos con la sustitución del marco alemán por la moneda única, más que una acción de juristas apolíticos deseosos de restablecer el principio de legalidad? Que los lectores juzguen.

49 Consistente en la compra de deuda soberana. Las inversiones se hacen por el Eurosistema a un ritmo de 80000 millones de euros cada mes.

50 Sir Walter Bagehot en su conocido libro Lombard Street: a description of the money market (1893), señaló cómo los bancos centrales deben ir a contracorriente de la sociedad para contrarrestar una crisis de confianza en los mercados, invitándoles en esos casos a «to lean against the wind». La crisis del euro ha sido, ni más ni menos, que una crisis de confianza, en la que el BCE — al igual que otros grandes bancos centrales - ha sido capaz de «inclinarse contra el viento» deflacionista y restaurar el funcionamiento normal de los mercados. 
